\title{
Políticas Públicas e Desenvolvimento da Tecnologia Nacional: o caso brasileiro em comparação aos países asiáticos ${ }^{1}$

\author{
Public Policies and National Technology Development: the brazilian \\ case compared to asian countries
}

\author{
Ricardo Luiz Sichel1,2 \\ Gabriel Ralile \\ ${ }^{1}$ Universidade Federal do Estado do Rio de Janeiro, Rio de Janeiro, RJ, Brasil \\ ${ }^{2}$ Universidade Cândido Mendes, Rio de Janeiro, RJ, Brasil
}

\begin{abstract}
Resumo
O presente artigo visa a compreender a relação entre políticas públicas, Propriedade Intelectual e desenvolvimento e sua relevância para o Brasil. Para tanto, foram analisados três casos de sucesso em desenvolvimento tecnológico: da China, da Coreia do Sul e de Taiwan, com fins de comparação ao caso brasileiro. Para a devida análise, utilizou-se material bibliográfico pertinente ao tema. Dessa forma, foram apresentados o histórico de cada país, as estratégias empregadas para o êxito de seus objetivos e os índices alcançados. Depois, fez-se um breve levantamento do caso brasileiro, sinalizando os pontos positivos e negativos presentes e os desafios pertinentes. Por fim, foi possível notar uma íntima relação entre Propriedade Intelectual, políticas públicas e desenvolvimento nacional, fatores que influenciam diretamente no crescimento nacional.
\end{abstract}

Palavras-chave: Desenvolvimento Nacional. Políticas Públicas. Propriedade Intelectual.

\begin{abstract}
The present article aims to understand the relationship between public policy, Intellectual Property and development and its relevance to Brazil. In order to do so, three cases of great success in the technology development field were analyzed for the sake of comparing it to the Brazilian situation: China, South Korea and Taiwan. For proper analysis, bibliographic material relevant to the topic was raised. In this way, the history of which country was presented, as well as the strategies used for the achievement of the desired objectives. After that, a short analysis of the Brazilian case was brought, signing both positive and negative aspects of it and, also, the pertinent challenges that continuous nowadays. Lastly, it could be noted that there is an intimate relationship between Intellectual Property, public policies and national developments, factors that directly influence national growth.
\end{abstract}

Keywords: Intellectual Property. National Development. Public Policy.

Áreas Tecnológicas: Estudos Baseados em Indicadores de Propriedade Intelectual. Competitividade Tecnológica. Inovação Tecnológica e Desenvolvimento.

${ }^{1}$ Artigo escrito no âmbito do Grupo de Pesquisa em Propriedade Intelectual da UNIRIO. 


\section{Introdução}

O presente artigo propõe uma abordagem sobre processo de desenvolvimento tecnológico de uma nação devido ao seu protagonismo nos tempos atuais para gerar bem-estar social e competitividade econômica. Ao se observar as diversas estratégias utilizadas por cada país, é possível verificar que umas estratégias tiveram mais êxito do que outras. Isso traz uma indagação do porquê de certos países conseguirem efetivamente lograr índices de desenvolvimento maiores que outros, ainda que em um mesmo período. Fato é que é perceptível que a interferência do Estado, por meio de políticas públicas e parcerias com o setor privado, deve criar condições para que haja o crescimento nacional, o que não é diferente na área de inovação e tecnologia.

Tendo isso em mente, uma pergunta recorrente é o motivo pelo qual o Brasil ainda possui certa defasagem tecnológica em relação a outros países, já que muitos deles iniciaram suas políticas de desenvolvimento mais tardiamente. Uma possível resposta para essa indagação seria a aplicação de um modelo eficiente de políticas públicas e de gestão da Propriedade Intelectual que permita o fomento da criação, proteção, transferência e utilização de novas tecnologias. Com vistas à compreensão de explicações para o atual cenário brasileiro, faz-se necessário uma comparação com o ocorrido em outras nações no século XX, muitas dessas que vieram a se estabelecer após a Segunda Guerra Mundial (1939-1945) como fruto da nova divisão global e da Guerra Fria.

Dessa forma, consideram-se as políticas públicas adotadas por três países selecionados de grande protagonismo na área de tecnologia e inovação: China, Coreia do Sul e Taiwan. Sobre o primeiro país, a especificação completa de seu nome tem por objetivo distingui-la do nome que muitos denominam: República da China, aqui denominada Taiwan. Na República Popular da China, o desenvolvimento ocorrido após o falecimento do líder revolucionário Mao Tse Tung teve que levar em consideração as cicatrizes de um doloroso período de perseguições, marcadas pelo fanatismo da Revolução Cultural. A despeito de seu caráter autoritário, o sistema chinês descortina um vertiginoso crescimento do Produto Interno Bruto (PIB), acompanhado de uma sociedade inovadora, que abandonou a natureza agrária para se engajar entre as nações mais ricas do mundo. Trata-se de um importante ator na seara do comércio global, cujos resultados não podem deixar de ser analisados. Deve-se, por óbvio, levar em conta que os números chineses assumem uma proporção grandiosa, até por causa do quantitativo demográfico.

Por sua vez, a Coreia do Sul é uma nação resultante do conflito das Coreias e possui uma das fronteiras de maior potencial explosivo no cenário global. O modelo sul-coreano, baseado em uma política de educação, acabou por transformar a parte mais pobre da península coreana, sob o aspecto de riqueza natural, em uma das nações mais desenvolvidas da atualidade. Nesse ponto, procuramos fazer uma análise desse processo de desenvolvimento econômico, ressaltando que se tratam de medidas implementadas com um horizonte de longo prazo. Essa perspectiva revela a visão do Estado Sul-Coreano em estabelecer os eixos fundamentais de desenvolvimento, que acabaram por incorporar novas tecnologias, em que a inserção destas, em especial no setor de telecomunicações, merece destaque.

Ainda, com uma formação advinda de um conflito bélico, tal como a Coreia do Sul, Taiwan foi fundada em 1949. Trata-se de uma ilha, no mar da China, surgida em função da fuga da República Popular da China dos aliados de Chan-Kai Sheck que tinham um objetivo, hoje considerado impossível, de um retorno ao continente. Essa nova nação, por meio de políticas 
orientadas, estabeleceu uma sociedade inovadora, na qual chama a atenção a quantidade de "Startups", empresas inovadoras, que, dada a sua simplicidade, se tornam impressionantemente ágeis na aplicação de novos conhecimentos e com isso geram um círculo virtuoso de desenvolvimento econômico e tecnológico.

O Brasil, ao contrário do ocorrido nos três casos anteriores, não se trata de uma nação surgida em função do término da Segunda Guerra Mundial ou como decorrência da Guerra Fria. Porém, apesar de uma série de tentativas, tem-se que certos setores foram impactados de forma bastante positiva quanto à inovação tecnológica. Porém, o que se evidencia é que o tão almejado desenvolvimento econômico ainda deixou de ser alcançado, dito que a sociedade ainda convive com mazelas do subdesenvolvimento, além da falta de continuidade na execução de políticas voltadas para esse fim. Deve ser levado em conta que a partir do final da década de 1980, o Brasil se reencontrou com a democracia, sendo que a Constituição de 1988 consagrou princípios básicos de livre iniciativa e concorrência. Isso, porém, deixou de estabelecer as necessárias condições para a eliminação dos sinais evidentes de miséria que ainda corroem o tecido social brasileiro.

Por fim, complementando a análise dos quatro casos, levou-se em consideração os indicadores de Propriedade Intelectual como dados mensuráveis dos índices de desenvolvimento tecnológico e, consequentemente, econômicos. A comparação entre os três casos e o cenário brasileiro tem o intuito de entender possíveis falhas no processo ocorrido no Brasil, bem como erros a serem evitados e desafios pertinentes.

\section{Metodologia}

O estudo foi elaborado por meio de um levantamento bibliográfico composto da compilação de dados históricos e de indicadores de Propriedade Intelectual dos países abordados: Brasil, China, Taiwan e Coreia do Sul. Para isso, em muito, foram abordadas as perspectivas e as análises trazidas por Eriksson, Arbix e Correa, entre outros autores. Ainda, o trabalho utilizou-se de dados levantados por instituições como o Instituto Nacional da Propriedade Industrial (INPI), a Organização Mundial da Propriedade Intelectual (OMPI), a Organização para a Cooperação e Desenvolvimento Econômico (OCDE) e o Fórum Econômico Mundial (WEF), além daqueles disponíveis em diversos meios na internet.

Para a elaboração do trabalho, seguiu-se um roteiro. Primeiramente, foi realizada a análise do ocorrido na República Popular da China. Depois, tratou-se do ocorrido na Coreia do Sul e, em seguida, passou-se ao modelo de desenvolvimento observado na anteriormente denominada República da China, atualmente Taiwan. Por fim, fez-se uma análise do Brasil com fins de entender suas diferenças em relação aos casos dos países asiáticos.

\section{Resultados e Discussão}

Por meio do material bibliográfico, indicadores de propriedade intelectual e demais dados levantados, foi possível traçar o perfil de desenvolvimento tecnológico e econômico de cada país em prol de compará-los. De uma forma geral, é possível verificar o nexo entre a produção de tecnologia nacional e o desenvolvimento do país como um todo. Ainda, ficou nítido que o 
papel do Estado como condutor desse processo por meio das políticas públicas é fundamental, uma vez que a presença da participação do governo nos casos dos países asiáticos justifica, em grande parte, a disparidade entre o nível de tecnologia encontrado nesses países e no Brasil.

O primeiro caso estudado foi o da República Popular da China, mais comumente conhecida apenas como China, que, sem dúvidas, é hoje uma das maiores potências mundiais em diversos ramos, inclusive quando se aborda a questão da inovação. É de se notar que a segunda maior economia mundial, tal como a conhecemos hoje, não vem se destacando no cenário internacional meramente por políticas recentemente adotadas, mas sim devido a um processo de longa data advindo sobretudo das reformas iniciadas em 1978.

Lideradas pelo secretário-geral do Partido Comunista Chinês (PCC) Deng Xiaoping, essas reformas tinham como orientação-base a construção e a modernização socialista por meio do "Programa das 4 modernizações", este responsável por desenvolver os setores de agricultura, indústria, defesa nacional e tecnologia (YUCING, 2013). Essa nova movimentação, em muito visando a sobrepor os estragos causados pela Revolução Cultural anos antes, impulsionou a industrialização chinesa, sua urbanização e a transição de uma planificação centralizada para uma abertura gradual de sua economia.

Nesse contexto, observamos três grandes etapas no viés produtivo chinês: um período com foco na agricultura, seguido de um maior protagonismo da manufatura e hoje um avanço a largos passos para o campo tecnológico-científico. Para entender grande parte dessa mudança, é preciso olhar para o Plano Estratégico Nacional de Médio e Longo Prazo para o Desenvolvimento da Ciência e Tecnologia (PENCT) implementado em 2006. O plano estratégico, que cobre o período até 2020, visa à inovação própria em áreas como eletrônicos e software, exploração de energia, meio ambiente e sustentabilidade. As prioridades de pesquisa foram estabelecidas em três campos: pesquisa básica, sem aplicação específica ou imediata; pesquisa aplicada, para resolução de problemas e melhoria das condições humanas; e desenvolvimento experimental, o uso do conhecimento obtido para produzir e melhorar produtos e processos, isto é, inovação. É importante salientar que um dos elementos-chave para a condução dessa política tem sido o fomento à educação.

Junto a isso, desde a implementação das reformas de Deng Xiaoping, o país vem promovendo um forte intercâmbio internacional de profissionais e permitindo a entrada de empresas em seu território como forma de captar tecnologia e conhecimento. Ainda, o país utilizou-se amplamente de acordos internacionais de cooperação na área de ciência e tecnologia. Segundo dados da embaixada do Reino Unido na China (2019), são 135 países e regiões com tratados de cooperação firmados, além de acordos com 86 países na área de cooperação técnica e econômica. Na ONU, o país participa de 30 instituições voltadas para a ciência e a tecnologia e, em nível mundial, participa de 827.

Visto isso, grande parte da qualificação de profissionais e o desenvolvimento de empresas gerado vêm sendo usados para atividades essenciais internas, promoção de missões no exterior, pesquisas, busca por soluções e inovação nas empresas e indústrias. A pesquisa de 2016 do Escritório Nacional de Estatísticas da China sobre Atividades de Pesquisa e Desenvolvimento (P\&D) e Patentes aponta que o número de profissionais trabalhando integralmente na dita área somava 2.702.489, enquanto os gastos com pesquisa chegavam a cerca de U\$ 15.760.308,00 distribuídos por 360.997 projetos (NATIONAL BUREAU OF STATISTICS OF CHINA, 2017). Nesse mesmo ano, o número registrado de invenções foi de 286.987, totalizando 769.847 que 
estavam sendo aplicadas. Não por coincidência, a China foi do oitavo lugar mundial em gastos com P\&D para o segundo em 2015, posição logo atrás dos EUA (CHINA POWER, 2016).

Os dados continuam exponenciais. Em matéria de pesquisa, já é um risco eminente que a China supere os Estados Unidos. Com 11 das cem melhores universidades ranqueadas no mundo, de 2000 a 2016, as publicações científicas chinesas quadruplicaram (ORSZAG, 2018). Esse desenvolvimento se dá em paralelo ao crescimento econômico e é alavancado pela iniciativa empresarial que representa $74,1 \%$ de participação, de acordo com dados da Organização para a Cooperação e Desenvolvimento Económico (OCDE) de 2015 (CHINA POWER, 2016). Inclusive, esse valor supera a média da própria OCDE, de 62,2\%, e dos EUA, 64,2\%.

Essa grande porcentagem se dá em muito pelo esforço do Partido em transferir os laboratórios de pesquisa governamentais para as empresas estatais e incentivar as entidades privadas, que aumentaram sua participação em 12\% (CHINA POWER, 2016). As instituições de ensino superior, por si só, também contribuem para o maior desenvolvimento de P\&D com uma participação de 9,4\%. O desafio está na tentativa de criar um canal direto entre as universidades e as companhias nesse setor, como é possível ver com a política de incentivos para que universidades criem e se tornem acionistas de empresas de tecnologia (BRASIL DEBATE, 2015). Como exemplo, pode-se citar a Lenovo, nascida de universidade e que cerca de $42 \%$ do capital pertence à Academia Chinesa de Ciências, organização científica de renome ranqueada em primeiro lugar na lista de 2015 da Nature Index sobre maiores instituições na área de ciências (O'MEARA, 2016).

Para fins de mensurar a inovação chinesa, um dos melhores indicadores a ser utilizado são os números de depósitos de patentes, visto que esses depósitos possuem forte equivalência ao número de invenções. O Escritório de Patentes e Marcas dos Estados Unidos concede patentes para o mundo todo, tendo concedido em 2016 mais de 300.000 patentes. De 2000 até a referida data, a participação dos países em desenvolvimento nessa quantidade se elevou de $1 \%$ para $6 \%$, sendo a China responsável por 4\% do total (WORLD ECONOMIC FORUM, 2018).

A inovação se torna evidente ainda, quando observado o avanço da internet na China. Em um período de 12 anos, o número de usuários multiplicou por sete, evidenciando política voltada para a integração digital como parte de uma estratégia de desenvolvimento econômico. A questão ultrapassa o limite da simples conectividade, mas as funcionalidades decorrentes dessa inserção, em face das potencialidades que exsurgem e pela amplitude do mercado a ser alcançado. A conectividade digital, além de alterar o funcionamento dos mercados, contribuiu para a aceleração do processo de desenvolvimento global. Nesse sentido, o uso da rede mundial de computadores constitui um indicativo a ser considerado (BARRERA, 2017).

De acordo com relatórios da Organização Mundial da Propriedade Intelectual (OMPI) (BERGQUIST; FINK; RAFFO, 2018), a China, em 2017, foi o segundo maior país com publicações científicas internacionais, ficando atrás apenas dos Estados Unidos, e alcançou o número de 2.444.482 trabalhos. Ainda, o país se qualificou como o terceiro maior depositário de patentes por meio do Tratado de Cooperação em Matéria de Patentes (PCT) com 305.311 entradas.

O relatório apontou também que 16 regiões chinesas estão entre os cem maiores clusters de ciência e tecnologia do mundo. Também, dentro de mais de 30 clusters chineses, a região de Shenzhen, em Hong Kong, e a capital Beijing se qualificaram, respectivamente, como os segundo e oitavo maiores níveis de performance global relativos a publicações científicas e depósitos de patente. 
Os altos índices de inovação podem ser percebidos como os resultados de uma política voltada às startups. O país já é o segundo no mundo com o maior número de unicórnios ${ }^{2}$, tendo investido em 2015 cerca de US $\$ 230$ bilhões em startups (STARTSE, 2018). Exemplos de sucesso são a já mencionada Lenovo, Estrelas Tech, Tencent, Xiaomi e Alibaba. Resta claro o forte vínculo entre iniciativa governamental, privada e instituições de pesquisa.

Por sua vez, esse mesmo grande êxito em utilizar as políticas públicas como alavanca para o desenvolvimento do sistema nacional de inovação pode ser percebido na Coreia do Sul. O país, que até os tradados de abertura de 1876-1883 tinha pouco contato com o mundo, hoje é uma das maiores potências na área de tecnologia.

Esse processo de evolução começou principalmente com a abertura do país, resultando em um período de profundo desenvolvimento que perdurou até a anexação japonesa em 1910. Com o final da Segunda Guerra Mundial e da dita colonização, o país emerge com uma aliança com o ocidente, porém carregando traumas dos tempos de dominação. A insegurança aumentaria com o acirramento dos conflitos internos, sucedidos pela Guerra da Coreia entre 1950 e 1953 e posterior divisão do país.

A secção da região em dois países em 1948 resultou na criação do que se conhece hoje como República Popular Democrática da Coreia, ou Coreia do Norte, e República da Coreia, mais conhecida como Coreia do Sul, rivalizadas sobretudo pela guerra perpetrada. Essa divisão acabou por estabelecer uma economia incompleta: não só o maior parceiro comercial, o Japão, não estava mais acessível, como houve a fragmentação da indústria entre o território do norte e sul.

Devido a tantos empecilhos e complexidades, em 1951 se iniciou uma reconstrução marcada por reformas e pelo forte apoio ao sistema educacional. De acordo com Michell (1998 apud ERIKSSON, 2005), a evolução da Coreia do Sul pode ser dividida em cinco fases: da colonização à independência econômica (1945-1950); a guerra das Coreias e reconstrução (1950-1959); do pequeno ao grande crescimento (1960-1969); o crescimento pela exportação (1970-1977); e o crescimento instável e recessão (1978-1982).

Por sua vez, o Banco Mundial divide a história do país em outras cinco etapas (ERIKSSON, 2005): guerra, reconstrução e reforma agrária (1950-1960); aumento das exportações (1961-1973); protagonismo da indústria química e pesada (1973-1979); incentivos funcionais e liberalização (1980-1990), liberalização do sistema financeiro (pós-1990).

Dentro dos ditos períodos, as estratégias que marcaram o desenvolvimento nacional foram o corporativismo estatal para auxiliar as empresas, o apoio aos Chaebol, termo para os conglomerados de empresas em torno de uma empresa-mãe, normalmente controladas por famílias, como Samsung, Hyundai e LG, e o controle sobre o sistema financeiro. A crise que atingiria o leste e o sudeste asiático na década de 1990 impactou a economia de tal forma que exigiu reformas para essas estratégias.

A tecnologia, nesse contexto, era um ativo importante e provinha majoritariamente do exterior, visto a restrição dada até 1983 ao investimento interno e ao investimento estrangeiro direto. A política coreana adotada era a de facilitar o aprendizado na indústria, aumentando, assim, a força competitiva, e a de prestar o suporte tecnológico.

${ }^{2}$ Startups avaliadas em mais de U\$1 bilhão. 
Nos anos de 1970 e 1978 marcou-se certa facilitação sobre as restrições, resultando em uma grande entrada de assistência técnica e, por consequência, uma maior quantidade de pagamento de royalties ao exterior (KIM, 1997 apud ERIKSSON, 2005, p. 19). Nas duas décadas seguintes, houve uma maior liberalização de transferência tecnológica, advindas em grande parte dos Estados Unidos e do Japão.

O sistema de inovação nacional sofreu uma forte propulsão na década de 1980 por meio das fortes relações instauradas entre o governo, iniciativas públicas e privadas para a promoção da tecnologia em diversos setores. Agentes relevantes foram os Chaebol, a Industrial Advancement Administration, que prestava suporte direto às empresas, e o Instituto Nacional de Tecnologia Industrial, para difusão de tecnologia e P\&D.

Desse ponto em diante, o avanço tecnológico passou a se pautar em P\&D nacional por meio de investimento direto e de incentivos independentes. O governo, como ao longo de toda a história, manteve certo papel participativo, mas em grande parte cedeu à descentralização e à privatização (ERIKSSON, 2005, p. 25). Isso levou ao surgimento dos grandes índices mensuráveis hoje, ainda que problemas como a dificuldade de transferência tecnológica universidade-empresa ainda perdurem.

Atualmente o reconhecimento da evolução tecnológica coreana é notável. De acordo com a lista da Thomson Reuters (2018) sobre as 100 empresas líderes em tecnologia do mundo, três são as maiores empresas do país no setor: LG, Samsung e SK Hynix. Ainda, segundo a base de dados da OCDE (2019b), a Coreia do Sul aumentou a participação de seu PIB em gastos com P\&D, em poder de compra por milhões, de U\$58.379,65 em 2011 para U\$90.979,63 em 2017. A natureza estratégica dessa questão é verificada pela política de desenvolvimento implementada pela Coreia do Sul, com investimentos privados, até 2023, de US $\$ 20$ bilhões (FISHER, 2019).

Compreender as ferramentas da tecnologia $5 \mathrm{G}$ foi objeto de análise de professores da Universidade de Cincinnati (MITRA, 2015, p. 133):

The society of 2020 will be a connected society. The IoT together with intelligent and integrated sensor systems and in-home sensor networks will change the way people lead their lives. "Smart living" people will require constant and ubiquitous mobile connectivity to the network to upload their activity data and IoT control commands, thus generating a "massive reporting" uplink data flow. Massive machine to machine communication and critical machine to machine communication will play pivotal roles in service delivery and industry operations.

Vehicular ad-hoc networks (VANETs) are constantly advancing. By 2020, VANETs integrated with cellular networks will be in operation as VANET cloud, leading to a smarter and safer transportation system.

When the number of devices connected to the Internet passes tens or hundreds of billions in the coming decade, the offloading of networked data on unlicensed bands will play a critical role in network load balancing, providing guaranteed bit rate services and a reduction in control signaling. Hence, it is important that $5 \mathrm{G}$ will provide seamless compatibility with dense heterogeneous networks to satisfy the high demand of real-time traffic, so that end users will experience smooth connectivity to the network. 
O país ainda conta com três dos maiores clusters do mundo, de acordo com a OMPI (BERGQUIST; FINK; RAFFO, 2018), sendo eles Seoul (terceiro lugar), Daejeon (23) e Busan (75'). A Organização também aponta que o país é o oitavo dos 20 maiores países em índices de publicações científicas, com 661.015 publicações, e entradas de patentes pelo PCT, 185.861.

Muito similar ao caso da Coreia, e fortemente conectada à história da China, é a trajetória de Taiwan. Também colônia japonesa até 1945, o país surgiu de conflitos internos por poder na China. Após a vitória do Partido Comunista Chinês, liderado por Mao Tse Tung, o Kuomintang foge do continente e se instaura na região insular onde hoje é Taiwan. Reivindicando o reconhecimento como a verdadeira China, apesar de ter pouco sucesso nesse objetivo, o país começa a traçar uma história de desenvolvimento fortemente apoiado pelo governo.

A evolução histórica de Taiwan pode ser dividida em cinco períodos (ERIKSSON, 2005, p. 28): reforma agrária e reconstrução (1949-1952); industrialização pelo processo de substituição de importação (1953-1957); promoção das exportações (1958-1972); consolidação industrial e novo aumento das exportações (1973-1980); e alta tecnologia e modernização (1981 em diante).

Até os anos de 1970, o país contou com amplo apoio dos Estados Unidos em uma estratégia de atuação governamental e liberalização das importações. Na década de 1990, por sua vez, a indústria intensiva em tecnologia ganhou uma maior importância, sobretudo a produtora de computadores e semicondutores, áreas de destaque nacional até hoje.

Essa transição é bem caracterizada pelo relevante aumento de índices econômicos: a indústria intensiva em tecnologia cresceu sua participação no setor manufatureiro de $24 \%$ em 1986 para 38,8\% em 1997, bem como as exportações de tecnologia nacionais aumentaram no mesmo período de $22,2 \%$ para $54,6 \%$ (ERIKSSON, 2005, p. 30).

A crise de 1997 surtiu pouco efeito sobre o país, o que foi um ponto extremamente favorável para o contínuo crescimento de sua economia e produção tecnológica. Nesse aspecto, foi lançado mão das seguintes estratégias para alcançar a tecnologia e inovação (KIM, 1998 apud ERIKSSON, 2005, p. 31): a construção de um recurso humano qualificado; a captação de tecnologia de peso advinda dos países mais desenvolvidos; o incentivo à ciência e a criação de capacidade tecnológica; e a capacidade de traduzir resultados de pesquisa em produtos comercializáveis.

Ainda, paralelamente, o país se usou da diminuição da taxação, da realização de empréstimos, do uso de instituições voltadas à informação e tecnologia, da gestão de aprovisionamento feita pelo governo, da proteção dada aos resultados de pesquisa, do cultivo às capacidades humanas, do auxílio de empresas em P\&D e nas demandas do mercado, bem como o forte investimento no sistema nacional de inovação (ERIKSSON, 2005, p. 34-35).

Os resultados alcançados hoje são extremamente expressivos. Na lista das 100 empresas líderes em tecnologia do mundo, 13 são de Taiwan. $\mathrm{O}$ índice é admirável e muito superior ao da rival China que ocupa apenas três posições na lista. Por sua vez, de acordo com dados da OCDE (2019a), houve um aumento da participação do PIB em gastos com P\&D de U\$27.542,61 milhões para U\$39.344,30 milhões entre 2011 e 2017. Nesse ponto, chama a atenção os desafios traçados por Taiwan, com vistas ao desenvolvimento econômico, conforme aponta Eriksson (2005): 
The main challenge facing the Taiwanese economic planners was how to move from a condition of little know-how, inadequate institutions, and an under-supply of trained scientists and engineers to that of a high-tech based economy. The key problem was how to keep upgrading the technological content of the products. To reach this goal an overall strategy of four key components was adopted (Lin, 1998).

- Building human resources.

- Acquiring technology from the more advanced countries.

- Creating science and technology capacities.

- Converting research results into commercial products.

Não obstante, o país é uma das maiores potências na área de computadores e semicondutores, ademais da recente participação e articulação internacional na confecção de aviões. Os relatórios de 2018 da OMPI (BERGQUIST; FINK; RAFFO, 2018) indicam a presença de dois clusters entre os 100 maiores do mundo: a capital Taipei, na $40^{\circ}$ posição, e Tainan-Kaohsiung na $87^{\circ}$. Apesar do pequeno tamanho, Taiwan sem dúvida é uma ilha de inovação.

Visto o processo de desenvolvimento tecnológico nesses três países, fez-se uma breve abordagem comparativa com o caso brasileiro. O Brasil, um dos primeiros signatários da Convenção da União de Paris para a proteção da Propriedade Industrial, sempre teve destacada participação nos foros internacionais, porém, em termos de resultados práticos e de um processo sustentado de desenvolvimento econômico, não se pode falar. Quando do estabelecimento do regime militar, em 1964, várias normas pertinentes à Propriedade Industrial foram editadas, a saber: o Decreto-lei n. 254/67 e o Decreto-lei n. 1.005/69, a Lei n. 5.772/71, como fruto da criação do Instituto Nacional da Propriedade Industrial (INPI), em 1970 (SOARES, 2011, p. 173).

Apesar de ser o ente autárquico competente para a concessão de direitos da Propriedade Intelectual, o INPI vem enfrentando dificuldades em cumprir essa tarefa. Essas dificuldades, por seu turno, impactam de forma negativa no processo de inovação tecnológica. Observando essa premissa, passa-se para a área finalística: tem-se um expressivo retardo nas decisões de pedidos de patentes, com graves repercussões no cenário global. Examina-se, hoje, pedidos com mais de 10 anos de trâmite. No campo de patentes, apresenta-se o seguinte gráfico, conforme aponta o relatório do próprio INPI: 
Gráfico 1 - Tempo médio de decisão, por divisão técnica, para pedidos decididos

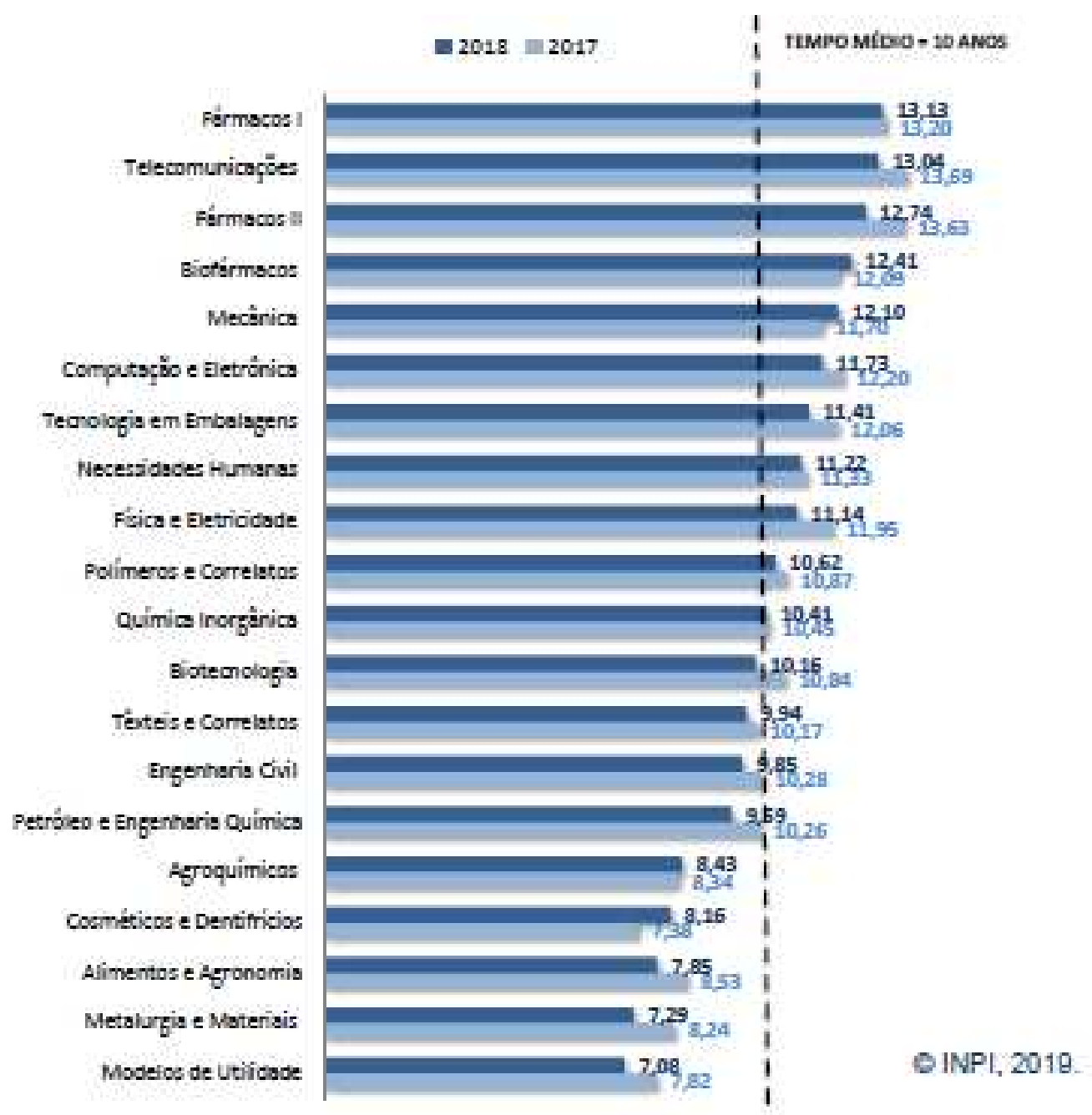

Fonte: INPI (2019)

Denis Borges Barbosa (2015, p. 41), relatando os incrementos utilizados pela tecnologia, aponta que o Japão, em seu processo de desenvolvimento econômico, se utilizou da tecnologia copiando produtos disponíveis, de forma a aprimorá-los e, dessa forma, desenvolvê-los, como base de criação e sustentação de seu desenvolvimento econômico. Por seu turno, o nível de proteção de Propriedade Intelectual, quando da transferência de tecnologia, tem impacto no campo de investimentos diretos nesse segmento, resultando que fraqueza nesse setor se concentra em países que as tomam, mediante licenciamento, por meio de sua importação.

Por outro lado, aqueles que detêm o conhecimento tecnológico estão mais propícios a licenciar seus produtos nos países com melhores padrões de proteção da Propriedade Intelectual (CORREA, 2000, p. 30). No que lhe concerne, o sistema de patentes pode ser encarado como sistema eficiente de fomento da tecnologia, caso haja algum desenvolvimento científico e tecnológico (CORREA, 2000, p. 39), não podendo passar in albis que o Brasil já detém expertise em vários destes, por exemplo, na prospecção de petróleo em grandes profundidades, confecção de aviões, agricultura, ou até em Institutos de Pesquisa, como a Farmanguinhos, o Butantã, entre outros. Esse entendimento é defendido por Robert Sherwood, que estatui que o incremento de investimentos em tecnologia tem como pressuposto uma melhora e o aprimoramento dos sistemas de proteção da Propriedade Intelectual (GUISE, 2006 p. 4). 
O Brasil dispõe de uma legislação bastante atualizada no que diz respeito às melhores práticas de $\mathrm{P} \& \mathrm{D}$, porém, conforme se observa do gráfico a seguir, o investimento, calculado sob a proporção do PIB ainda é baixo, principalmente se comparado com outras nações (ARBIX 2017, p. 55).

Gráfico 2 - Investimento em P\&D em comparação ao PIB por país

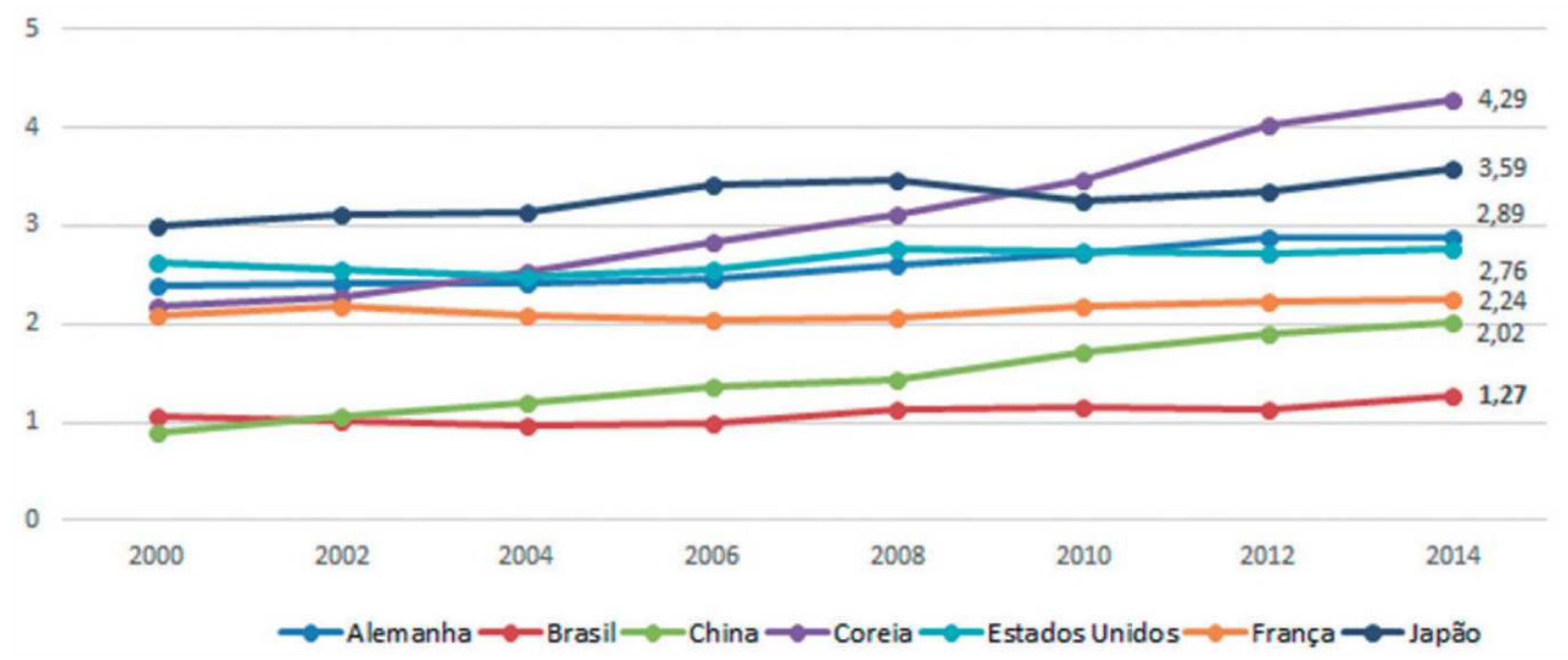

Fonte: Arbix (2017, p. 55)

O que se observa dos dados apresentados no Gráfico 2 é a falta de continuidade de políticas voltadas para o fomento do processo de inovação tecnológica e sua proteção. Pelo contrário, a instabilidade do marco regulatório tem feito com que o patamar de desenvolvimento econômico brasileiro deixe de seguir, em especial quanto ao ritmo e à evolução, os resultados observados na República Popular da China, na Coreia do Sul e em Taiwan. Trata-se de uma questão que passa inexoravelmente por uma reflexão do papel a ser desempenhado pelo INPI, que seja ágil e seguro, no tocante a decisões a serem tomadas, como também em relação às universidades, como elemento-base para o desenvolvimento de políticas de Pesquisa e Desenvolvimento (P\&D). No entanto, ainda assim é possível perceber que as iniciativas de participação nas discussões internacionais sobre Propriedade Intelectual e o estabelecimento de uma normativa interna deveras contribuem para certo nível tecnológico, indicando o papel fundamental da Propriedade Intelectual para o desenvolvimento tecnológico.

\section{Considerações Finais}

Vistos e analisados os casos, resta clara a íntima relação entre Propriedade Intelectual, políticas públicas e desenvolvimentos nacional. A capacidade de inovação de um país e seu desenvolvimento tecnológico-científico não apenas criam recursos fundamentais para a competitividade das empresas, mas também fazem transbordar seus benefícios para a população como um todo, seja pelos seus resultados ou pelos rendimentos trazidos.

Ademais, é nítida a participação do setor privado, em integração ao governo $e$ aos demais entidades nacionais, nesse processo, sendo, portanto, tanto uma peça-chave para o fomento das 
políticas públicas como também alvo delas. Isso acaba por ilustrar bem a dinâmica do sistema nacional de inovação, indicando o papel de liderança do governo em sua organização.

Quando nos atentamos ao caso dos países asiáticos mencionados, é visível a influência de políticas públicas de longo prazo no desenvolvimento e processo inovativo nacional. Sendo países formados, tal como os conhecemos hoje, após a Segunda Guerra Mundial e durante o período de Guerra Fria, é impressionante a rápida evolução alcançada por eles.

China, Coreia do Sul e Taiwan contaram com políticas intensivas nas áreas de educação, tecnologia e pesquisa, bem como se utilizaram de instrumentos financeiros e econômicos para criar arcabouços para tal. Ainda, é evidente a participação internacional no processo, seja pela importação de conhecimento e tecnologias, como pelo intercâmbio de pessoal.

O Brasil, por sua vez, historicamente marca presença nas discussões internacionais sobre Propriedade Intelectual e possui casos de sucessos em setores como o de petróleo, construção de aviões e agricultura. Contudo, diferentemente dos casos anteriores, sua política pública não foi contínua, sobretudo pela instabilidade do marco regulatório, o que levou a certa estagnação no processo de desenvolvimento nacional.

O que se pode retirar de tais análises é a importância da formulação de políticas de longo prazo, em consonância com os demais setores da sociedade e embasados por um arcabouço legal estável para o desenvolvimento nacional. É claro que a Propriedade Intelectual se serve nesse meio como peça de fomento e segurança para que o processo inovativo seja bem desenvolvido, como observado nos casos de uso de patentes e transferência de tecnologia. Cabe, então, o aprendizado com os episódios de sucesso e uma devida elaboração de estratégias que possibilitem fomentar o crescimento econômico e geração de bem-estar.

\section{Referências}

ARBIX, G. Políticas de inovação em nova chave. Estudos Avançados, São Paulo, v. 31, p. 49-73, 2017.

BARBOSA, D. B. Ensaios e estudos de Propriedade Intelectual 2014-2015: Volume III. Edição do Instituto Brasileiro da Propriedade Intelectual, 2015. 806 p.

BARRERA, Alex. Forget Silicon Valley: Innovation is happening in China now. [2017]. Disponível em: https://becominghuman.ai/forget-silicon-valley-innovation-is-happening-in-china-nowc6cfdbd74bc4. Acesso em: 15 jun. 2019.

BERGQUIST, K.; FINK, C.; RAFFO, J. Identifying and ranking the world's largest science and technology clusters. [2018]. Disponível em: https:/www.wipo.int/edocs/pubdocs/en/wipo_pub_ gii_2018-chapter14.pdf. Acesso em: 14 jun. 2019.

BRASIL DEBATE. A aposta chinesa na inovação. [2015]. Disponível em: http://brasildebate.com. br/a-aposta-chinesa-na-inovacao/ Acesso em: 14 jun. 2019.

CHINA POWER. Is China a global leader in research and development? [2016]. Disponível em: https://chinapower.csis.org/china-research-and-development-rnd/ Acesso em: 14 jun. 2019.

CORREA, C. Intellectual Property Rights, the WTO and Developing Countries. 2. ed. Londres: Zed Books, 2000. 
EMBASSY OF THE PEOPLES'S REPUBLIC OF CHINA IN THE UNITED KINGDOM OF GREAT BRITAIN AND NORTHERN IRELAND. International Science and Technology Exchange and Coorperation. [2019]. Disponível em: http://www.chinese-embassy.org.uk/eng/zygx/st/t27120.htm. Acesso em: 14 jun. 2019.

ERIKSSON, S. Innovation Policies in South Korea and Taiwan. Suécia: Vinnova, 2005. 72p. FISHER, T. When Is 5 G Coming to South Korea? (Updated for 2019). Disponível em: https:// www.lifewire.com/5g-south-korea-4583813. Acesso em: 14 jun. 2019.

GUISE, M. Propriedade intelectual no mundo contemporâneo: fomento ao desenvolvimento? In: XV CONGRESSO NACIONAL DO CONPEDI - CONSELHO NACIONAL DE PESQUISA E PÓSGRADUAÇÃO EM DIREITO, 2006. Anais [...]. 2006.

INPI - INSTITUTO NACIONAL DA PROPRIEDADE INDUSTRIAL. Metas e resultados: balanço da gestão 2015-2018. [2019]. Disponível em: http://www.inpi.gov.br/arquivos/INPI_metas_e_resultados_ balanco_gestao_20152018.pdf. Acesso em: 14 jun. 2019.

LYRIO, M. C. A ascensão da China como potência: fundamentos políticos internos. 2. ed. Brasília: Fundação Alexandre de Gusmão, 2010. 250p.

MITRA, R. 5G mobile technology: a survey. ICT Express Volume 1, Issue 3, December 2015, Pages 132-137, Seocho-gu: 2015. (Korea Institute of Communication Sciences)

NATIONAL BUREAU OF STATISTICS OF CHINA. China statistical yearbook 2017. Disponível em: http://www.stats.gov.cn/tjsj/ndsj/2017/indexeh.htm. Acesso em: 14 jun. 2019.

OCDE - ORGANIZAÇÃO PARA A COOPERAÇÃO E DESENVOLVIMENTO ECONÔMICO.

Chinese innovation. [2019a]. Disponível em: http://oecdobserver.org/news/archivestory.php/ aid/2496/Chinese_innovation_.html. Acesso em: 15 jul. 2019

OCDE - ORGANIZAÇÃO PARA A COOPERAÇÃO E DESENVOLVIMENTO ECONÔMICO.

Main science and technology indicators. [2019b]. Disponível em: https://stats.oecd.org/Index. aspx?DataSetCode=MSTI_PUB. Acesso em: 14 jun. 2019.

O'MEARA, S. Ten institutions that dominated science in 2015. [2016]. Disponível em: https:// www.natureindex.com/news-blog/ten-institutions-that-dominated-science-in-twentyfifteen. Acesso em: 14 jun. 2019.

ORSZAG, P. R. China Is Overtaking the U.S. in Scientific Research. [2018]. Disponível em: https:/www.bloomberg.com/opinion/articles/2018-09-12/chinese-researchers-are-outperformingamericans-in-science. Acesso em: 14 jun. 2019.

OYENIRA, R.; UWAMAHORO, E. Impacts of Reforms in Chinese Educational System. [2019]. Disponível em: http://www.macrothink.org/journal/index.php/ije/article/viewFile/10495/8733. Acesso em: 14 jun. 2019.

SOARES, R. Regime jurídico de proteção à propriedade industrial no Brasil. Revista Direito e Liberdade, Natal, v. 13, n. 1, p. 157-172, 2011. (Revista Direito e Liberdade da Escola da Magistratura do RN)

STARTSE. Mergulhando no ecossistema empreendedor da China. [2018]. Disponível em: https://lp.startse.com.br/material-rico/e-book-mergulhando-no-ecossistema-empreendedor-da-china/. Acesso em: 2 jul. 2019. 
THOMSON REUTERS. Top 100 global tech leaders 2018. [2018]. Disponível em: https:/www. thomsonreuters.com/en/products-services/technology/top-100.html. Acesso em: 6 jul. 2019.

WORLD ECONOMIC FORUM. China is an innovation superpower this is why. [2018].

Disponível em: https:/www.weforum.org/agenda/2018/02/these-charts-show-how-china-is-becomingan-innovation-superpower/. Acesso em: 14 jun. 2019.

YUCING, G. G. China o impacto das reformas econômicas chinesas dentro e fora do país. [2013]. Disponível em: https://pucminasconjuntura.wordpress.com/2013/09/07/china-o-impacto-dasreformas-economicas-chinesas-dentro-e-fora-do-pais/. Acesso em: 2 jul. 2019.

\section{Sobre os Autores}

\section{Ricardo Luiz Sichel}

E-mail: ricardo.sichel@unirio.br

Doutor em Direito Europeu de Patentes pela Westfälische Wilhelms Universitat Münter em 2002. Professor associado da Escola de Ciências Jurídicas da UNIRIO e professor do Programa de Mestrado em Direito da Universidade Cândido Mendes (RJ).

Endereço profissional: Av. Pres. Vargas, n. 446, Centro, Rio de Janeiro, RJ. CEP: 20070-030.

\section{Gabriel Ralile}

E-mail: ralilegabriel@gmail.com

MBA em Comércio Exterior pela Universidade Federal do Rio de Janeiro em 2019. Graduação em Direito em andamento pela Universidade Pública do Rio de Janeiro. Pesquisador do Grupo de Pesquisa de Propriedade Intelectual da Universidade Federal do Estado do Rio de Janeiro.

Endereço profissional: Av. Pres. Vargas, n. 446, Centro, Rio de Janeiro, RJ. CEP: 20070-030. 